\title{
EXPERIENCE REPORT OF THE INCLUSION OF PATIENTS WITH IMRD IN THE MÁRIO PINOTTI II PROJECT IN MANAUS-AMAZONAS
}

Samuel Elias Basualto Dias ${ }^{1, \star}$, Vitória Miki Pang Takatani', Clara Pinheiro Martins', Cecília Tizatto Barroso', Gabriella Bacellar Marques ${ }^{1}$, Joelma Moreira Belas Torres', Bárbara Letícia Costa Corrêa', Gabriela Alarcón Alcântara', Bruna Borges Santos', Gabriel Antônio de Lima Cerqueira', Bruna Guimarães Dutra', Laura Ribeiro Aref Kzam¹, Andrezza Mendes Franco', Gabriel Pacífico Seabra Nunes ${ }^{2}$, Isabela de Araújo Seffair', Matheus Diniz Araújo Teixeira', Marianna Maisonnette de Attayde Silva', Giordana Farnese', Raissa Pires de Medeiros¹, Davi Queiroz Rêgo', Lucas Basílio Simonetti Cabral', Marcelo Veloso Gouveia de Melo1, Gustavo Lopes de Castro', Henrique Euzébio Guedes de Freitas², Yane Melo Santana², Thais de Arruda Reinehr², Heitor Torres Garrido, Ranna Simões e Souza1, Micaella Oliveira Costa¹, Douglas Ferreira dos Santos', Roland Guilherme Ferreira Vermehren², Victória Pereira Ferreira², Fernanda Maria da Silva Bezerra', Tayana Evelling Uchôa da Silva', Juliana Bühring ${ }^{1}$, Bárbara Seabra Carneiro', Helena Lúcia Alves Pereira1', Sandra Lúcia Euzébio Ribeiro

1.Universidade Federal do Amazonas, Manaus (AM), Brazil. 2.Universidade Nilton Lins, Manaus (AM), Brazil.

${ }^{*}$ Corresponding author: samuel.ebd@gmail.com

\section{BACKGROUND}

Coronavirus disease 2019 (COVID-19) has become of worldwide importance and, aiming at knowing more about the effects of this new disease and possible treatments, several research groups mobilized, among them, the Brazilian Society of Rheumatology, which started the Mario Pinotti II project (MPII), with the objective of evaluating the preventive effect of antimalarials (AM), hydroxychloroquine and chloroquine, in patients with immune-mediated rheumatic diseases (IMRD) in chronic use of AM. The objective of this study is to report the inclusion process and the benefits of the project in Manaus (Amazonas).

\section{MATERIALS AND METHODS}

Descriptive study based on the inclusion process via telephone survey of patients with IMRD from the MPII project in Manaus. Information regarding the methods of patient selection and organization, contact methods and the difficulties encountered during the inclusion period were analyzed.

\section{RESULTS}

Inclusion period was from April 28 to May 17, 2020 in Manaus. The team was composed of three rheumatologists, three residents in rheumatology and 32 students from 7th to 12th period. An Excel spreadsheet was organized by the students, in which residents and rheumatologists entered data (name, phone and IMRD) of 637 patients to be contacted by phone. Due to the difficulty in the calls and seeking to improve the effectiveness of the contact, WhatsApp was used to send a previous message identifying the team, project and objectives, for later contact. During the contacts, the lack of AM in Manaus was identified, both in pharmacies and in the central of medicines of Amazonas (CEMA-SUS). The team mobilized to collect donations, collecting chloroquine (1,000 pills) and hydroxychloroquine (12,000 pills), to make the project viable until September. Of the 637 patients, 311 were included and 326 were excluded (165 for not being able to contact, 78 for exclusion criteria, of which 68 for not using BF for more than 15 days, 55 had never used BF, 9 did not accept to participate and 19 for others unidentified reasons).

\section{CONCLUSION}

The importance of this project in Manaus can be emphasized, as it was possible to identify the lack of AM and provide clinical follow-up for these patients in the face of the pandemic. The team was able to alleviate the clinical and emotional symptoms with individual care to patients and family members, favoring more effective ways of adapting to the pandemic. In addition, there were exchanges of reactive emotional experiences present in the professional activity of the entire project team. 